\title{
Por uma didática mídia-educativa
}

\author{
Joana Sobral Milliet ${ }^{1}$
}

\section{Resumo}

O artigo apresenta subsídios para se pensar caminhos em direção a uma didática mídiaeducativa usando como metodologia a revisão bibliográfica motivada pelos resultados de uma pesquisa extensa realizada nas escolas municipais do Rio de Janeiro. A partir da constatação - ancorada pelos dados da pesquisa - de que as escolas ainda não incorporaram em suas práticas as principais diretrizes postas hoje pelo campo da Mídia-educação, aborda a importância do letramento midiático para a formação de cidadáos que possam se relacionar de forma crítica e criativa com as mídias e relata as barreiras elencadas por pesquisadores para a implementação das TIC nas escolas. Por fim, o artigo aponta um caminho a partir da construção de políticas públicas mídia-educativas com diretrizes claras e mecanismos que garantam sua implementação na didática em sala de aula, incorporando fundamentalmente: 1 - infraestrutura; 2 - formação continuada de professores; 3 - incentivos para que os professores implementem a política, com autonomia para criarem práticas pedagógicas diversas, liberdade para a invençáo e espaço para o erro.

Palavras-chave: didática; mídia-educação; letramento midiático; políticas públicas.

\section{Toward a media education didactic}

\section{Abstract}

The article presents subsidies for thinking paths towards a media-educational didactics using as methodology the literature review motivated by the results of an extensive research carried out in the municipal schools of Rio de Janeiro. From the finding - anchored by the research data - that schools have not yet incorporated into their practices the main guidelines put today by the field of Media Education, it addresses the importance of media literacy to form citizens who can relate critically and creatively to the media and reports the barriers listed by researchers for the implementation of ICT in schools. Finally, the article points a way from the construction of media educational public policies with clear guidelines and mechanisms that ensure their implementation in classroom didactics, fundamentally incorporating: 1 - infrastructure; 2 - continued teacher training; 3 - incentives for teachers to implement the policy, with autonomy to create diverse pedagogical practices, freedom for invention and space for error.

Key words: didactics; media education; media literacy; public policies.

1 Doutoranda em Educação pela PUC-Rio. E-mail: joanamilliet@gmail.com. 


\section{Introdução}

O impacto causado pelas tecnologias da informação e comunicação (TIC) abrange os mais variados âmbitos da sociedade contemporânea, passando pelos processos econômicos, políticos e sociais, transformando nossos valores, as formas como nos relacionamos e aprendemos na atualidade. Assim, mais do que apenas ferramentas, as TIC devem ser vistas enquanto artefatos culturais, "ambientes imersivos que modificam substancialmente as práticas, crenças e hábitos da nossa sociedade" (PISCHETOLA, 2018, p. 189).

No Brasil, dados da pesquisa TIC Domicílios $2017^{2}$ apontaram que a proporção de usuários de internet no país é de $67 \%$, o que significa, em números absolutos, 120,7 milhóes de brasileiros acessando a rede, sendo que nas áreas urbanas essa proporção é de $71 \%$. Ainda de acordo com a pesquisa, $87 \%$ deles usam a internet todos os dias ou quase todos os dias, sendo o celular o dispositivo mais utilizado por quase a totalidade dos usuários (96\%). Diante dessa realidade, nas últimas décadas, o campo da educação tem discutido o papel da escola na formação de cidadãos capazes de se relacionar de forma crítica e criativa com as TIC. Imersas em uma cultura digital, as crianças desde pequenas já têm contato diário com as TIC, principalmente quando estão fora da escola. A pesquisa TIC Educação $2017^{3}$ apontou que $85 \%$ das crianças e adolescentes brasileiros, de 9 a 17 anos, são usuários de internet, sendo que apenas 39\% dos alunos de escolas públicas de áreas urbanas e $50 \%$ daqueles que estudam em escolas particulares afirmaram acessar a internet na escola.

Entendendo as TIC como artefatos culturais que modificam o ambiente humano, um dos principais desafios enfrentados pela escola hoje é a integração das diferentes mídias a um projeto pedagógico que propicie ao aluno interagir com essas novas tecnologias de forma autônoma, crítica e ativa. Orozco (2010) diz que na "condição comunicacional contemporânea" temos a oportunidade de interagir de maneira real com os produtos midiáticos, graças à interatividade que o digital permite, e não apenas de maneira

2 A pesquisa TIC Domicílios é realizada pelo Centro Regional de Estudos para o Desenvolvimento da Sociedade da Informaçáo CETIC. Br anualmente desde 2005 com o objetivo de mapear o acesso à infraestrutura de TIC nos domicílios urbanos e rurais do país e as formas de uso destas tecnologias por indivíduos de 10 anos de idade ou mais.

3 Pesquisa também realizada pelo CETIC. Br anualmente desde 2011 com o objetivo de mapear o acesso, o uso e a apropriaçáo das tecnologias de informação e comunicação (TIC) em escolas públicas e privadas de educação básica. 
simbólica como era anteriormente, na dimensão analógica. Agora podemos "desconstruir comunicacionalmente" os referentes midiáticos, sendo capazes de ressemantizá-los, destruí-los e reconstruí-los tanto materialmente como informacionalmente (p. 16). Por isso, Orozco (idem) ressalta que um dos grandes desafios contemporâneos é o desenvolvimento de competências comunicativas para sermos, enquanto audiências, não apenas receptores, mas também produtores e emissores. Assim o autor afirma a necessidade de uma política comunicacional-educativa, que busque fortalecer as capacidades de produção comunicativa dos cidadãos: "Porque assim como não se nasce receptor de TV ou rádio, mas torna-se um, também não nascemos emissores, transmissores ou criadores, temos que aprender a sê-lo" (OROZCO, 2010, p. 17, tradução nossa).

Nesse sentido, proponho nesse artigo uma discussão teórica usando como metodologia a revisão bibliográfica motivada pelos resultados de uma pesquisa extensa que levantou projetos e práticas de mídia-educaçáo nas escolas municipais do Rio de Janeiro (TAVARES; DUARTE; JORDÃO, 2016; DUARTE; MILLIET; MIGLIORA, 2019). Busca-se refletir sobre quais seriam as principais barreiras para a implementação das TIC nas escolas e pensar caminhos no sentido da implantação de uma didática mídia-educativa.

\section{Mídia-educação e novos letramentos}

Denominamos a discussão teórica sobre as relações entre as mídias e a educação e as experiências práticas realizadas nesse âmbito, de mídia-educação, ${ }^{4}$ "um campo teórico e prático que deve dar conta da convergência inédita na história da humanidade dos processos de comunicação e educação" (BELLONI, 2002, p. 30). Em muitos países do globo, a mídia-educação está presente não só nas discussóes acadêmicas, mas também nas práticas escolares e nas políticas públicas de educação. No contexto social brasileiro, as diversas experiências nesse campo provocam invençóes e cria-

4 Entre os campos que tratam da convergência entre a comunicação e a educação há diferentes abordagens, sendo as mais difundidas no Brasil a Mídia-educação e a Educomunicação. A Mídia-educação tem origem na Media Education oriunda da Inglaterra e demais países da Europa nos anos 1970. Já a Educomunicação surge associada aos movimentos sociais na América Latina, a partir da década de 1960 e não tem como foco a educação escolar, mas propõe intervençốes em espaços de educação formal e não formal para o desenvolvimento de ambientes propícios à pluralidade expressiva e à participação (COSTA, 2016). 
ções mídia-educativas, que nem sempre relacionam teoria e prática e muitas vezes não são denominadas como mídia-educativas (FANTIN, 2014). Epistemologicamente, a mídia-educação pode ser compreendida como "área de saber e de intervenção; como práxis educativa com um campo metodológico e de intervenção didática; e como instância de reflexão teórica sobre esta práxis (com objetivos, metodologias e avaliação) em contexto escolar e extraescolar" (FANTIN, 2014, p. 49). A mídia-educação configura-se, portanto, como fundamental para os processos de socialização das novas gerações, visando a formação de cidadãos capazes de utilizar as mídias como meios de participação, conhecimento, expressão e criatividade.

Uma das discussóes mais caras ao campo da mídia-educação são as novas formas de literacia ou letramento, que ao longo dos anos foi recebendo diferentes designaçóes - digital, da internet, midiático e transmidiático - a partir da construçáo e desenvolvimento dos conceitos por diversos autores. Segundo Magda Soares (2002), os novos letramentos exigem novas práticas e habilidades de leitura e escrita para se atribuir sentido, selecionar e avaliar o que se vê nas telas, incluindo textos, imagens, sons, hipertextos etc., e também para se produzir conteúdo através dessas múltiplas linguagens. Marcelo Buzato (2010) afirma que esses novos letramentos são híbridos na medida em que são constituídos por tecnologias, códigos, atitudes e valores presentes e adquiridos na interação com as mídias, que se entrelaçam e modificam mutuamente. Dessa forma, ser letrado seria participar desse conjunto de práticas sociais nos quais os sentidos dos conteúdos codificados culturalmente são gerados, disputados, negociados e transformados.

Sonia Livingstone (2011) refere-se especificamente ao conceito de "literacidade na internet", que para a autora pode ser diferenciada de outras formas de literacidade, na medida em que habilidades específicas, experiências e valores culturais associados à internet são distintos daqueles relacionados a outras formas de comunicação. Entre suas particularidades estão desde o conhecimento sobre o uso do hardware até competências interpretativas e avaliativas envolvendo conteúdos e serviços, ou aquelas reguladas socialmente que incluem normas, regras e acordos aceitos pelos usuários.

Além das habilidades cognitivas, motoras e sociais para o letramento midiático, Eshet-Alkalai (2012) aborda também a importância das habilidades socioemocionais. $\mathrm{O}$ autor sugere um modelo conceitual que compreende seis habilidades para o uso de ambientes digitais: 1. Foto-visual (leitura de mensagens representadas visualmente); 2. Reprodução digital (criação de 
um novo material a partir de outros já existentes); 3. Ramificação (construção de conhecimento a partir de navegação não linear e hipertextual); 4. Informacional (habilidade de avaliar a qualidade e validade das informaçóes); 5. Socioemocional (habilidade de escapar das armadilhas da internet e saber trabalhar de forma colaborativa); e 6. Raciocínio em tempo real (capacidade de utilizar ambientes digitais avançados que exigem que o usuário processe simultaneamente grandes volumes de estímulos em tempo real e alta velocidade). Segundo Eshet-Alkalai (idem), o letramento socioemocional é o mais complexo dos seis e para adquirir essa habilidade, os usuários devem ser muito críticos, analíticos e maduros, além de ter um alto grau de letramento informacional e de ramificação.

O conceito de literacia transmídia é abordado por Carlos Alberto Scolari (2018), e expande os postulados da literacia midiática, complementando-os a partir de uma leitura diferente da realidade midiática dos jovens. A literacia transmídia tem como foco principal o que os jovens fazem com as mídias fora do contexto escolar, considerando-os prosumers (produtores + consumidores), capazes de partilhar e gerar conteúdos midiáticos de diferentes tipos e níveis de complexidade. As capacidades transmidiáticas ${ }^{5}$ são uma série de competências no contexto das novas culturas colaborativas relacionadas com a produçáo, partilha e consumo de mídias digitais interativas, que vão desde processos de resolução de problemas em games até a produção e partilha de conteúdo em plataformas web e redes sociais.

Os conceitos sobre os novos letramentos apontam para a necessidade de adquirirmos competências e habilidades midiáticas de ordens diversas. Se no senso comum as geraçóes atuais de crianças e adolescentes são reconhecidas como "nativos digitais" (PRENSKY, 2001), as pesquisas sobre o tema não têm comprovado essa retórica. Em seu conhecido ensaio, Mark Prensky cunhou os termos "nativos digitais" e "imigrantes digitais" para designar os que nasceram e se formaram utilizando a linguagem digital e as geraçóes mais velhas, que se depararam com as tecnologias já na vida adulta. Assim,

5 A pesquisa Transmedia Literacy, realizada de 2015 a 2018, envolveu 8 países e criou uma taxonomia de capacidades transmidiáticas. "Trata-se de um dos mapas mais exaustivos de capacidades relacionadas com a produção, consumo e pós-produção de media já realizados no contexto da cultura transmediática dos jovens. As capacidades transmediáticas identificadas durante a investigaçáo foram divididas em 9 dimensóes (produção, prevenção de risco, performance, gestão de conteúdo individual e social, media e tecnologia, ideologia e ética, narrativa e estética), incluindo cada uma delas 44 capacidades principais e, num segundo nível, 190 capacidades específicas" (SCOLLARI, 2018, p 9). 
de acordo com o autor, o "nativo digital" tem habilidades com as novas tecnologias, é acostumado à grande quantidade e velocidade de informaçóes e a realizar múltiplas tarefas ao mesmo tempo, além de utilizar as TIC para seu aprendizado.

As pesquisas sobre essas práticas têm mostrado, no entanto, que há na grande maioria dos casos, entre as geraçóes mais novas, apenas habilidades instrumentais e técnicas no manuseio e uso das TIC. Fantin (2016) revela que em suas pesquisas estudantes demostravam dificuldades extremas em competências básicas e seu uso das TIC era limitado apenas ao que lhes interessava nos dispositivos. Pischetola e Heinsfeld (2018) identificam, a partir de uma pesquisa com professores de oito escolas municipais do Rio de Janeiro, que estes valorizam apenas as habilidades técnicas dos alunos com o uso de tecnologias e não consideram outros tipos de habilidades fundamentais para o letramento midiático, como as informacionais e estratégicas. As autoras enfatizam ainda a necessidade de se superar a ideia de que a geração atual de crianças e adolescentes já sabe usar as TIC simplesmente por terem nascido na época da sua difusão.

\section{Práticas mídia-educativas nas escolas}

No XIX ENDIPE" realizado em 2018, cujo tema foi "Para onde vai a Didática? O enfrentamento às abordagens teóricas e desafios políticos da atualidade", Candau (2018) apresentou questóes consideradas urgentes para a reconfiguração da Didática no mundo atual, entre elas os impactos provocados pelas Tecnologias da Informação e Comunicação (TIC) nos processos de ensino-aprendizagem. Diante da constatação de que as mídias alteram nossos modos de construir conhecimentos e subjetividades, a autora aponta que o potencial transformador do uso das TIC nas práticas pedagógicas é ainda subestimado, já que muitas vezes não chega a afetar a dinâmica do professor, sendo utilizada apenas como uma ferramenta de apoio ao trabalho já estabelecido.

6 XIX Encontro Nacional de Didática e Práticas de Ensino, realizado em Salvador, em setembro de 2018. 
Uma pesquisa $^{7}$ realizada de 2015 a 2017 pelo Grupo de Pesquisa Educação e Mídias (Grupem), da PUC-Rio em parceria com o Instituto Desiderata e a Gerência de Mídia-Educação da Secretaria Municipal de Educação, fez um levantamento dos projetos e práticas de mídia-educação das escolas municipais do Rio de Janeiro. Os resultados da etapa quantitativa com a participação de $91 \%$ das escolas de Ensino Fundamental da rede, mostraram que, entre as escolas participantes, $92 \%$ afirmaram possuir práticas mídia-educativas, contudo, nas perguntas subsequentes, muitas escolas negaram a existência de diversas atividades, ou assinalaram que as realizavam em periodicidade muito baixa (TAVARES; DUARTE; JORDÁO, 2016). Duarte et al. (2019) analisam esses resultados e apontam que as práticas de análise crítica de conteúdos de mídias (atividades que colocam em debate ou em questão conteúdo e forma de filmes, programas de televisão e rádio, publicidade, fotografia, imagens em geral, fotojornalismo, telejornalismo, sites, blogs, entre outros materiais veiculados nas mídias) estão mais consolidadas na rede municipal do Rio de Janeiro, enquanto as práticas de produção de mídias (produção de materiais com uso de mídias - escrita de textos em diferentes gêneros, vídeos, arquivos de áudio, web rádio, blogs, páginas na internet, jornais on-line ou impressos, entre outros materiais de mídia) ainda estão em estágio inicial de desenvolvimento. Além da precariedade da infraestrutura nas escolas, Duarte et al. (2019) destacam alguns fatores que podem ser associados à pouca produção de mídias em contexto escolar: a falta de reconhecimento da sociedade brasileira sobre a importância do letramento midiático, "entendido muitas vezes como uma habilidade meramente técnica, que seria desenvolvida 'naturalmente' com o uso de mídias digitais" (p. 8); a falta de debate público sobre democratizaçáo dos meios; a quase inexistência de práticas de produção de mídias nos cursos de formação inicial de professores; e o valor menor conferido pelos meios educacionais aos materiais produzidos em outras linguagens que não a escrita.

Os resultados da pesquisa mostram que as escolas da Rede Municipal de Educação do Rio de Janeiro, reconhecida por ter implementado políticas

7 A pesquisa Projetos de Mídia-Educação nas escolas da rede pública municipal do Rio de Janeiro foi realizada em duas etapas: a primeira, de base quantitativa com análises qualitativas, teve como foco identificar se, como e com que frequência são desenvolvidas práticas mídia-educativas nas escolas de Ensino Fundamental. A segunda etapa, de cunho qualitativo, teve como objetivo compreender mais profundamente o funcionamento, a estrutura e a organização das práticas de mídia-educaçáo nas escolas municipais e foi realizada através de observaçôes em visitas a 8 escolas. 
de mídia-educação (especialmente pela criação, em 1993, da MultiRio ${ }^{8}$ ), ainda não incorporaram em suas práticas as principais diretrizes postas hoje pelo campo. Nessa perspectiva, pesquisas diversas vêm investigando os motivos que levam à dificuldade de se implementar a mídia-educação nas escolas. Esteves, Fiscarelli e Souza (2015) fazem uma análise das dez barreiras para a adoção das TICs na escola, apresentadas no relatório BECTA, ${ }^{9}$ comparando-as com dados colhidos pelo $\mathrm{CETIC}^{10}$ a partir de entrevistas feitas com professores brasileiros. As dez barreiras abordadas são: 1) falta de confiança e ansiedade dos professores frente às TIC; 2) falta de competência do professor; 3) falta de acesso aos recursos; 4) falta de tempo; 5) problemas técnicos; 6) resistência às mudanças e atitudes negativas; 7) não percepção de benefícios; 8) impacto nos exames públicos; 9) diferenças de idade; e 10) diferenças de gênero. Os autores sugerem um agrupamento dessas barreiras, a partir da avaliação se elas estão relacionadas com os professores (barreiras pessoais, como, por exemplo, falta de confiança, falta de acesso aos recursos, falta de percepção dos benefícios, falta de tempo), ou à instituição (barreiras para a instituição escolar, como falta de treinamento eficaz, problemas técnicos, também a falta de tempo, entre outros). Concluem que entender até que ponto essas barreiras afetam os indivíduos e as instituiçóes pode ajudar a decidir como superá-las, sem deixar de considerar que existem relaçóes complexas entre as barreiras em cada nível.

Quase todas as barreiras listadas pelo relatório BECTA aparecem constantemente nos discursos sobre as dificuldades de implementação das TIC na Didática. Magda Pischetola (2018), a partir dos resultados de suas pesquisas, reflete a respeito dos discursos que estão no senso comum sobre as dificuldades de introduçáo das TIC no cotidiano escolar. O primeiro deles é a ideia das tecnologias como suporte ou apoio ao trabalho do professor, pois, segundo a autora, "a condição de ferramentas de suporte implica o fato de que existe uma didática instaurada e estabelecida, que não será modificada com a presença de algumas ferramentas a mais” (p. 189). Assim,

8 Produtora de Multimeios vinculada à Secretaria Municipal de Educação da Prefeitura da cidade.

9 BECTA, originalmente conhecida como Agência Britânica de Comunicações Educacionais e Tecnologia, era um órgão público não-departamental financiado pelo Departamento de Educação, no Reino Unido, voltado para a promoção e integração de tecnologia da informação e comunicação (TIC) na educação. Foi extinta em 2010.

10 CETIC - Centro de Estudos sobre as Tecnologias da Informação e da Comunicação, é o departamento do NIC.br responsável pela coordenação e publicação de pesquisas sobre a disponibilidade e uso da Internet no Brasil. 
as práticas continuam iguais, apenas tendo o digital enquanto suporte. $\mathrm{O}$ segundo discurso muito comum é o das TIC como aliadas do professor e da educação, sendo utilizadas para tornar as aulas mais interessantes. Por trás dessa ideia está a concepção de que as TIC são apenas diversão e prazer, diferente da seriedade do conhecimento científico valorizado pela cultura escolar. Assim, não se considera as TIC enquanto artefatos culturais, que devem ter seus usos discutidos e mediados pela escola. Finalmente, o terceiro discurso apontado pela autora questiona algumas barreiras apresentadas pelo relatório BECTA. Suas pesquisas realizadas na última década mostram que não há resistência do professor e nem a idade apresenta-se como um fator negativo. Pelo contrário, os professores mostram-se curiosos e dispostos a inovar suas práticas. As dificuldades, portanto, seriam por problemas burocráticos, infraestruturais e técnicos, todos também apontados no relatório BECTA como barreiras relacionadas à instituição.

\section{Consideraçóes finais}

São muitos os obstáculos identificados para a implantação de uma didática mídia-educativa nas escolas brasileiras. Pischetola (2018) enfatiza que é fundamental que os professores entendam que o uso das TIC altera as metodologias, os tempos e espaços, sendo necessárias mudanças estruturais na sala de aula. Transformaçóes essas que mexem profundamente com o formato escolar, concebido na modernidade a partir de sua lógica, mas que permanece até hoje, sendo um dos grandes desafios discutidos no campo da Didática (CANDAU, 2018).

Diante das barreiras e dos paradigmas que resistem na realidade das escolas, uma didática mídia-educativa só se efetivará com a formulação de políticas públicas de mídia-educação. Apesar da emergência do campo nos estudos acadêmicos nacionais e internacionais, e de sua presença nas políticas educacionais de diversos países, no Brasil ainda não há uma política nacional de mídia-educação. Os programas desenvolvidos pelo Governo Federal ${ }^{11}$ nas últimas décadas têm como viés a inserção das TIC nas escolas pautados geralmente por três eixos centrais: distribuição de equipamentos,

11 No âmbito Federal vimos surgirem programas como o Proinfo - Programa Nacional de Informática na Educação, que teve início em 1997 e uma década depois passou a se chamar Programa Nacional de Tecnologia Educacional; o Banda Larga nas Escolas, lançado em 2008; e o Prouca, Programa Um Computador Por Aluno, lançado em 2009, que distribuía laptops para os alunos. 
formação de professores e produção de material didático digital. No entanto, tais programas são caracterizados por uma linha marcadamente tecnicista e instrumental (CASTRO, 2016), ficando, portanto, restritos à inserção da tecnologia na escola sem a preocupaçáo com a construção de pensamento crítico. Observa-se, ainda, na concepção dessas políticas, uma ausência de diálogo com as pesquisas acadêmicas e os fundamentos da mídia-educação já colocados para o campo (FANTIN, 2014).

Assim, torna-se necessário formular e implementar políticas que garantam infraestrutura nas escolas (equipamentos e internet de qualidade) e formação continuada de professores com noções teóricas sobre o campo e indicações metodológicas que ensinem possíveis aplicações didáticas das TIC (PISCHETOLA, 2018). Fundamentalmente, as políticas mídia-educativas devem ter diretrizes claras com relação aos letramentos midiáticos e à inclusão do debate sobre os aspectos éticos, estéticos e políticos das TIC (DUARTE et al., 2019). Além disso, é preciso que na política estejam previstos incentivos para que os professores implementem suas diretrizes em sala de aula com autonomia para criarem práticas pedagógicas diversas, liberdade para a invenção e espaço para o erro.

Como afirma Candau (2018), é preciso que a Educação dê respostas aos desafios postos pela contemporaneidade e, nesse sentido, incorporar as potencialidades pedagógicas das mídias parece ser essencial para o que a autora considera urgente na atualidade: a reinvenção da escola a partir da construção de novos formatos escolares, de maneiras diferentes de organizar o tempo e o espaço escolar e de dinamizar os processos de ensino-aprendizagem.

\section{Referências}

BELLONI, M.L. Mídia-educação ou comunicação educacional? Campo novo de teoria e prática. In: BELLONI, M.L. (org.). A formação na sociedade do espetáculo. São Paulo: Loyola, 2002. p. 27-45.

BUZATO, M. (2010). Cultura digital e apropriação ascendente: apontamentos para uma educação 2.0. Educ. rev., Belo Horizonte, v. 26, n. 3, p. 283-303, dez. 2010.

CANDAU, V. M. Didática: novamente 'em questão'? In: XIX ENDIPE, Salvador, 2018. 
CASTRO, M.C. Correlaçöes entre uso pedagógico de tecnologias de informaçāo e comunicaşão e desempenho escolar: análise envolvendo dados da TIC Educação 2011 e Prova Brasil. Tese (Doutorado em Educação) - Rio de Janeiro: Pontifícia Universidade Católica do Rio de Janeiro, 2016.

COSTA, E. R. Educomunicação e Midiaeducação: um estudo comparativo entre as cidades de Sao Paulo e Rio de Janeiro. In: Eliana Nagamini. (org.). Série Comunicação e Educação Volume 1 Questôes teóricas e formação profissional em Comunicação e Educação. Iheus: Editus, 2016, v. 1, p. 89-107.

DUARTE, R.; MILLIET, J.; MIGLIORA, R. Projetos e práticas de mídia-educação nas escolas públicas municipais do Rio de Janeiro.Educą̧ão $e$ Pesquisa. São Paulo, v. 45, e202710, 2019. Disponível em: http://www.scielo. br/scielo.php?script=sci_arttext\&pid=S1517-97022019000100584\&lng= pt\&nrm=iso.

ESHET-ALKALAI, Y. Thinking in the digital era: A revised model for digital literacy. Issues in Informing Science \& Information Technology, v. 9, p. 267-276, 2012.

ESTEVES, R.F.; FISCARELLI, S.H.; SOUZA, C.G. As barreiras para implementação das TIC na sala de aula. Revista Ibero-Americana de Estudos em Educação, [S.l.], v. 9, n. 3, p. 583-598, mar. 2015.

FANTIN, M. Contextos, perspectivas e desafios da mídia-educação no Brasil. In: ELEÁ, Ilana. Agentes e Vozes: um panorama da Mídia-educação no Brasil, Portugal e Espanha.Gothenburg: Nordicom., 2014. p. 49-57

FANTIN, M. Nativos e imigrantes digitais em questão: crianças e competências midiáticas na escola. Passagens, Fortaleza,v. 7, n. 1, p. 5-26, 2016.

LIVINGSTONE, S. Internet literacy: a negociaçáo dos jovens com as novas oportunidades on-line. In: Matrizes. Ano 4 - n. 2, jan./jun. 2011, p. $11-42,2011$

OROZCO G. G. Hacia una cultura de participación televisiva de las audiências. Ideias para su fortalecimiento. Comunicação, Mídia e Consumo. São Paulo. v. 7, n. 19, p. 13-31, 2010.

PISCHETOLA, M. Cultura Digital, tecnologias de informaçáo e comunicação e práticas pedagógicas. In: CANDAU, V. (org.). Didática: 
tecendo/reinventando saberes e práticas. Rio de Janeiro: 7 Letras, 2018. p.186-201.

PISCHETOLA, M.; HEINSFELD, B. D. S. S. "Eles já nascem sabendo!”: desmistificando o conceito de nativos digitais no contexto educacional. Renote. Revista Novas Tecnologias na Educação. v. 16, 2018. p.1-10.

PRENSKY, M. Digital natives, digital immigrants In: PRENSKY, Marc. On the horizon. MCB: University press, vol. 9, n.5. outubro 2001.

SCOLARI, C. A. (2018). Literacia transmedia na nova ecologia mediática. Relatório de Pesquisa. Disponível em: http://transmedialiteracy.upf.edu/ sites/default/files/files/TL_whit_port.pdf. Acessado em: dez. 2018.

SOARES, M. Novas práticas de leitura e escrita: letramento na cibercultura. Educ. Soc. [on-line]. 2002, v. 23, n. 81, p.143-160.

TAVARES, M. T.; DUARTE, R. M.; JORDAO, C. Prática mídia-educativa de análise de produtos e conteúdos midiáticos nas escolas da Prefeitura do Rio de Janeiro. Educação e Cultura Contemporânea (on-line), v. 13, p. 323349, 2016.

Recebido em: 26 ago. 2019.

Aceito em: 12 nov. 2019. 